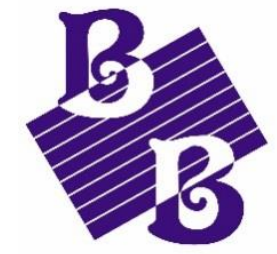

BioBacta
Journal of Bioscience and Applied Research www.jbaar.org

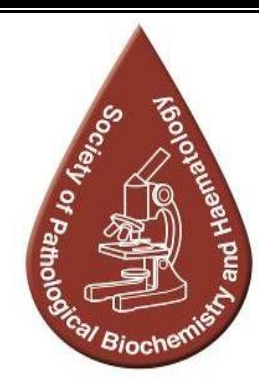

\title{
Biochemical and immunocytochemical studies of the testicular alteration caused by Amitriptyline in adult male rat
}

\author{
*Ehab Tousson, Somia Zaki, Ezar Hafez, Amani Gad \\ Department of Zoology, Faculty of Science, Tanta University, Tanta, Egypt \\ *Corresponding author: toussonehab@yahoo.com \\ DOI: 10.21608/jbaar.2018.152508
}

\begin{abstract}
Amitriptyline is one of the first reference tricyclic antidepressants (TCAs) with sedative and analgesic properties. This study aimed to investigate the testicular indices that influenced by amitriptyline treatment and examined it by biochemical, histological and Immunohistochemical methods. A total of 20 male albino rats were equally divided into two groups: the first was control and the second was amitriptyline intoxicated group. The results of this study showed that amitriptyline consumption significant decrease hormones parameters, increase sperms abnormalities, decrease sperm numbers, induced testicular tissue damage and P53 alterations.
\end{abstract}

Keywords: Amitriptyline- Antidepressant- reproductive hormones- testis- sexual dysfunction.

\section{Introduction}

Amitriptyline (AMT), a tricyclic antidepressant that is a dibenzocycloheptadine derivate, is frequently used especially in neuropsychiatry for depression, depressive personality disorder and nocturia. Amitriptyline is one of the first reference tricyclic antidepressants (TCAs) with sedative and analgesic properties (Millan, 2002; Khurshid et al., 2017). Amitriptyline acts as a serotonin-norepinephrine reuptake inhibitor, thereby increasing the concentration of these transmitters in the synapse (Owens et al., 1997). Amitriptyline undergoes extensive metabolism in the liver, primarily through $\mathrm{N}$-demethylation, to nortriptyline. Paths of metabolism of both amitriptyline and nortriptyline include hydroxylation and N-oxidation (Otaka et al., 2005). Within the liver, the drug is primarily metabolized by the action of cytochrome P450 enzymes, namely, CYP2D6, CYP3A4, and CYP2C19(Beverly et al., 2005).
In addition to inhibiting presynaptic reuptake of noradrenaline and serotonin, amitriptyline has an affinity for $\alpha$ adrenergic, histamine, muscarinic cholinergic, 5-HT, N-methyl-Daspartate (NMDA) and opioid receptors which responsible for its side effects. Common side effects include drowsiness, dizziness, dry mouth, constipation and sweating, irregular heartbeat, blurred vision or problems passing water (Rogan and Roth, 2011; Mickle et al., 2012; Tondo and Baldessarini, 2016). So, this study aimed to investigate the testicular indices that influenced by amitriptyline treatment and examined it by hormonal levels, sperms quality and quantity, testes structure and apoptotic P53 marker alterations.

\section{Materials and Methods Experimental animals}

The experiment was performed on 20 male albino rats (Rattus norvigicus) weighing $150 \mathrm{~g}$ $( \pm 10)$ and 9-10 weeks' age. They were obtained 
from the animal house of the National Research Center (Dokki, Giza, Egypt). The rats were housed in suitable plastic cages for one week before the experimental work for acclimation with anew room conditions and maintained on a standard rodent diet, with water available $a d$ libitum. During the experiment, animal behaviour was noticed and body weight at the beginning and the end of the experiment were measured. Animal procedures were performed following the Ethics Committee of the National Research Centre, Giza, Egypt.

\section{Experimental groups}

The rats were randomly and equally divided into 2 groups (10 rats each).

G1: a control group that included animals that did not receive any treatment during the experimental period.

G2: Amitriptyline (Tryptizol; El Kahira Pharm And Chem Ind Co) group in which rats were injected intraperitoneally with Amitriptyline (70 $\mathrm{mg} / \mathrm{kg}$ body weight/daily) for four weeks (Hajhashemi et al., 2011).

\section{Blood samples}

Serum was collected from the inferior vena cava and separated by centrifugation at 3000 rpm for 15 minutes. The collected serum was stored at $-18^{\circ} \mathrm{C}$ until analysis for estimation of blood parameters (Testosterone, LH, FSH, Prolactin hormones).

\section{Biochemical investigations}

Determination of Serum Luteinizing Hormone (LH) was assayed according to Odell et al. (1974), Serum Testosterone Level according to Delacerda et al. (1973), Serum Follicle Stimulating Hormone (FSH) Level by the method of Odell et al. (1981) and serum prolactin hormone levels was assayed by the method Duhau et al. (1991).

\section{Sperms morphometric analysis}

Testes and epididymis were carefully removed, cleaned from adhering connective tissue in cold saline and weighed. Epididymitis was prepared for fertility evaluation to evaluate sperm counting, spermatozoa motility parameters and sperm morphology a computer-assisted semen analysis (CASA System; Germany) with Olympus microscope (Olympus, Tokyo, Japan) was used according to the method of Adamkovicova et al. (2016).

A total of 200 spermatozoa from each rat were examined and individually scored normal or abnormal, according to the strict sperm morphology criteria according to Wang et al. (2016).

\section{Histopathological examination}

Testis was fixed with $10 \%$ buffer neutral formalin solution for 48 hours and then processed for paraffin sectioning. $5 \mu \mathrm{m}$ Sections were stained with haematoxylin and eosin for histopathological examination according to Bancroft and Gamble, (2002).

\section{Immunohistochemical detection apoptotic protein:} P53

Expression of P53 in the testis and epididymis sections were detected using the avidin Biotin Complex (ABC) method according to Tousson et al., (2018).

\section{Statistical Analysis}

Data were expressed as mean values \pm SE and statistical analysis was performed using an unpaired t-test to assess significant differences among treatment groups. The criterion for statistical significance was set at $p<0.05$ for the biochemical data. All statistical analyses were performed using SPSS statistical version 21 software package (SPSS ${ }^{\circledR}$ Inc., USA).

\section{Results}

\section{Toxicity}

Many side effects have appeared on rats after Amitriptyline administration such as weakness, loss of activity, increased perspiration and increased or decreased appetite.

\section{Reproductive hormones}

Groups intoxicated by amitriptyline (G3) showed a significant decrease in levels of serum testosterone at $(\mathrm{p}<0.0001)$, serum FSH at $(\mathrm{P}<0.0001)$, serum $\mathrm{LH}$ at $(\mathrm{p}<0.0001)$ and serum prolactin at $(\mathrm{p}<0.0001)$ compared with a control group (G1) (Figures 1-4).

\section{Sperms changes}

Our results revealed that; the sperm motility and sperm abnormality exhibited a significant decrease $(P<0.05)$ in the Amitriptyline group when compared with a control group (G1) (Figures 5\&6).

Meanwhile, Figures (5\&6) show the sperm abnormalities of rats treated with Amitriptyline group (G2), the percentage of sperm with head defect (no head) has been increased significantly in the Amitriptyline group (G2) as compared with a control group; also, there is a significant increase in another head defect like double head, amorphous, banana shape, hookless head, pinhead sperms in Amitriptyline group (G2) as compared with a control group (G1) (Figure 6). 


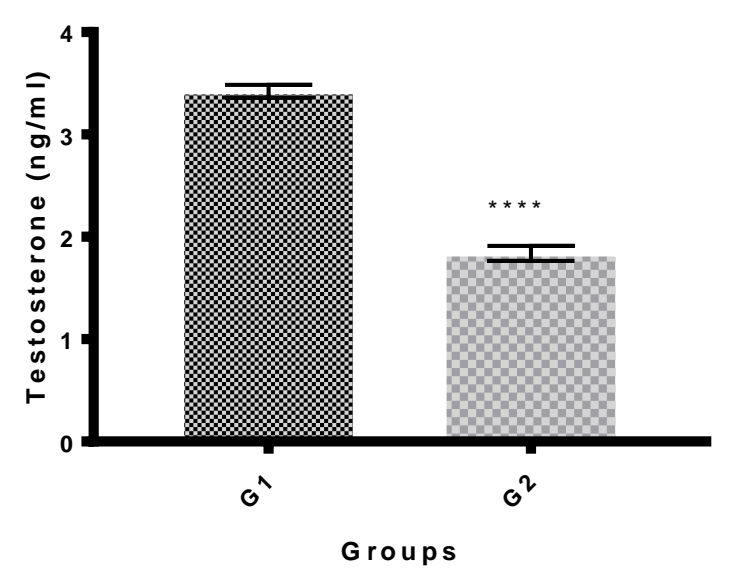

Figure 1: Means of serum testosterone concentration (ng/ml) in experimental groups. Where, G1, control group and G2, Amitriptyline group.

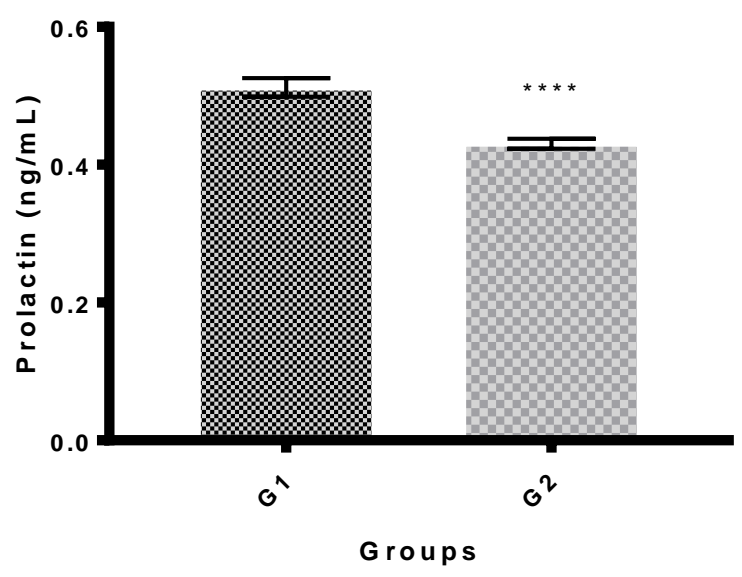

Figure 2: Means of serum prolactin $(\mathrm{ng} / \mathrm{mL})$ in experimental groups. Where, G1, control group and G2, Amitriptyline group.

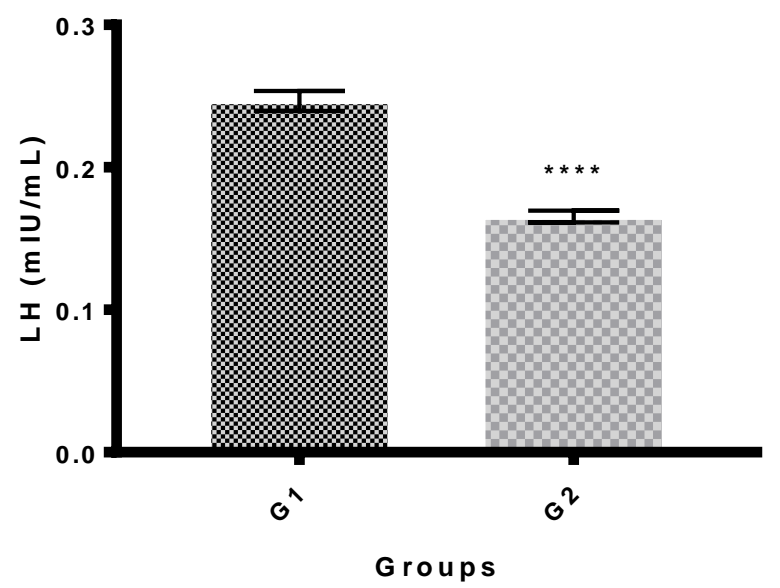

Figure 3: Means of serum luteinizing hormone (LH; (mIU\Ml) in experimental groups. Where, G1, control group and G2, Amitriptyline group.

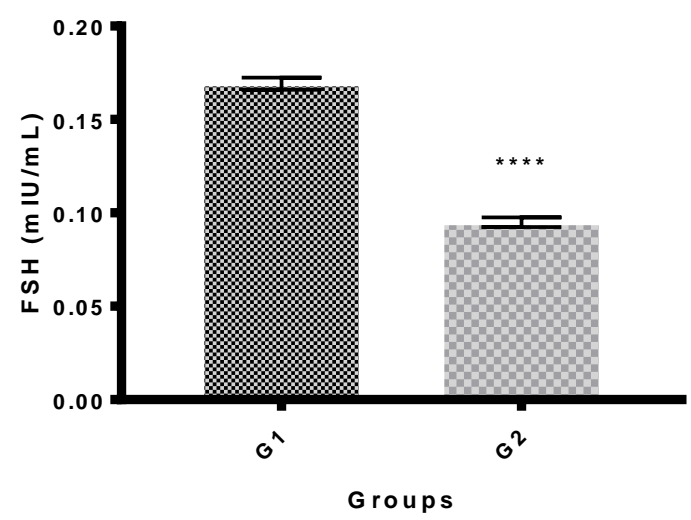

Figure 4: Means of serum follicle-stimulating hormone FSH $(\mathrm{mIU} / \mathrm{ml})$ in experimental groups. Where, G1, control group and G2, Amitriptyline group.
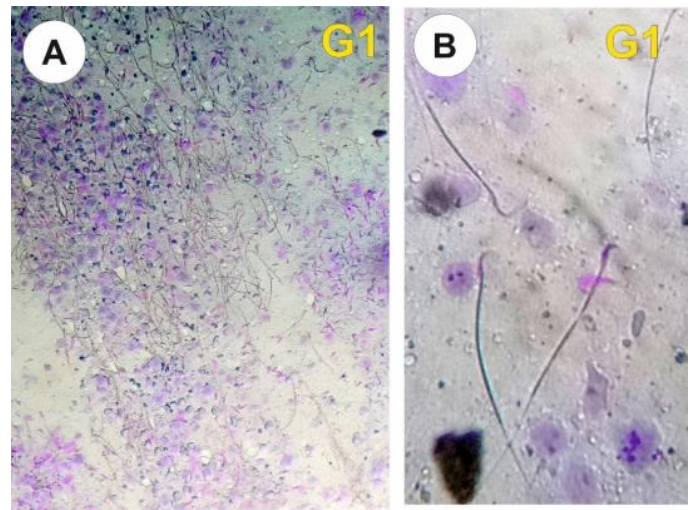

Figure 5: Microphotographs illustrating morphologically normal sperm (A\&B).
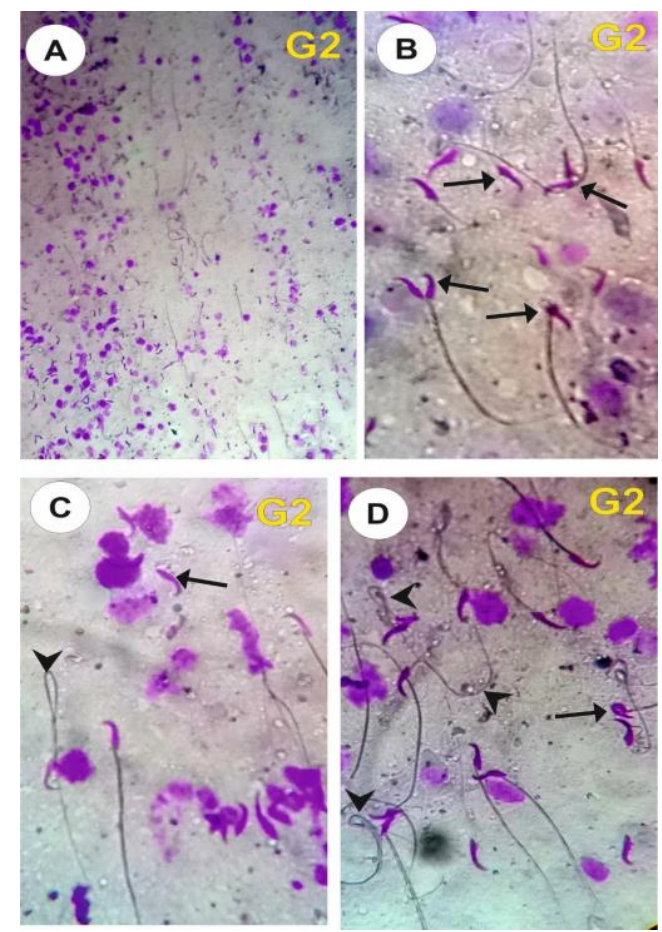

Figure 6: Microphotographs illustrating morphologically abnormal sperm (A-D) in Amitriptyline group (G2) with various sperm defects as double head; amorphous head, fused heads, bent head, hook head and coiled tail. 


\section{Histopathology results}

Histopathological study showed that the cycle of spermatogenesis is regular in all-male rats in the control (G1) group (Figures 7A). The structural components of the testis are the seminiferous tubules and interstitial cells (Leydig cells).

Two types of cells are identified in rat seminiferous tubules, the Sertoli cells and the spermatogenic cells. Sertoli cells were found resting on the thin basal lamina (basement membrane) while the spermatogenic cells were arranged in many layers and identified as spermatogonia, primary spermatocytes, secondary spermatocytes, spermatids and finally mature spermatozoa (Figure 7A).

Testis sections of the Amitriptyline group (G2) revealed disturbance and not a regular cycle of spermatogenesis in seminiferous tubules, a significant decrease in the number of spermatogenic cells in the seminiferous tubules, marked thickened in the basement membrane, moderate vacuolar degenerative changes in the cytoplasm of the spermatogenic epithelium and the Sertoli cells, decrease and abnormal distribution of spermatozoa was seen in the lumen of the seminiferous tubules and a significant decrease in the numbers of Leydig cells (Figure 7B).

\section{Apoptotic P53 immunohistochemical changes in testis}

Testes sections in the control (G1) group showed negative or faint positive reaction for P53 expressions in the Leydig cells while other cells in the semi nefarious tubules showed negative reaction for P53 expressions (Figure 8A). Testes sections in Amitriptyline treated rat group (G2) showed a strong positive reaction for P53 expressions in the Leydig cells (Figures 8B\&8C).

\section{DISCUSSION}

Testicular toxicity is an important safety endpoint in drug development and risk assessment. Systematic reviews of the epidemiology of sexual difficulties, dysfunction, and dissatisfaction indicate that sexual problems are common in men and women in all societies and more frequent in older individuals and among those with chronic medical conditions, including depression (Derogatis and Burnett, 2008; Lewis et al., 2010). The present study, provided that amitriptyline retards testicular growth and impairs spermatogenic functions. Amitriptyline in high dose produced a significant decrease in the testosterone, prolactin, FSH and $\mathrm{LH}$ hormones in experimental rat groups (G3; Amitriptyline only). So, Amitriptyline changes the hormonal levels and disrupts the testosterone and estrogens ratio which illustrate, the toxic effects of the amitriptyline disrupted sex hormone and can lead to sexual dysfunction and infertility. These results were in line with most studies in this field such as Clayton and Montejo, (2006), Bahmanpour et al. 2009, Williams et al., (2010) and Badr El-Din and A. Abd-El Aty, (2012), who elucidate the effects of drugs on sexual dysfunction and spermatogenesis appear to be due to changes in hormones level such as testosterone, $\mathrm{LH}, \mathrm{FSH}$ and prolactin.
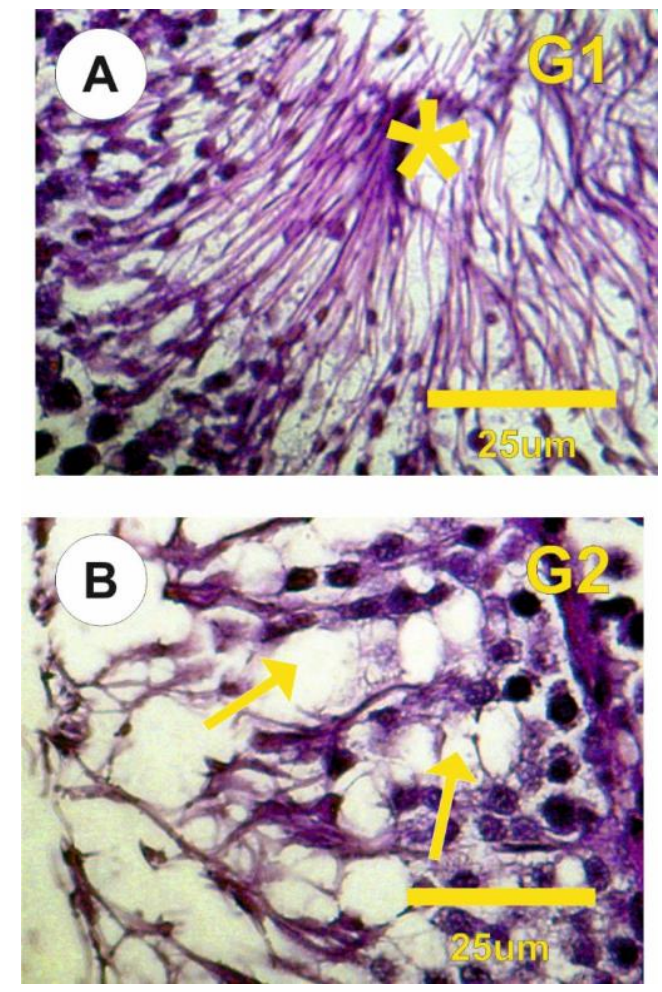

Figure (7): Photomicrographs of rat testis sections in the different groups stained with Haematoxylin \& Eosin. A: Testes sections in the control (G1) group showed a regular cycle of spermatogenesis in the seminiferous tubules and normal structure of interstitial cells (Leydig cells) and the lumen full of sperms (stars). B: Testis sections of the Amitriptyline group (G2) revealed disturbance and not a regular cycle of spermatogenesis in 
seminiferous tubules, moderate vacuolar degenerative changes in the cytoplasm (yellow arrows), decrease and abnormal distribution of spermatozoa and decrease in the numbers of sperms.
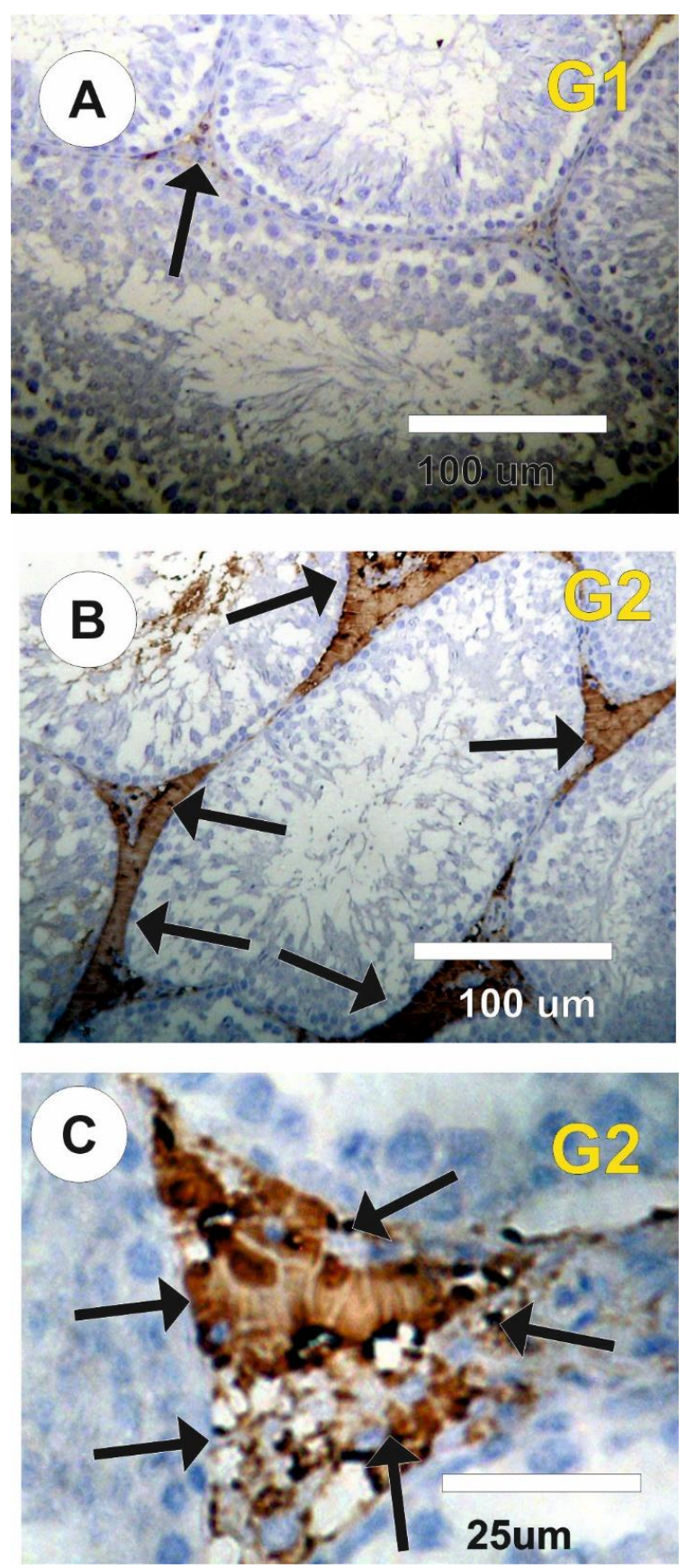

Figure 8(A-C): Photomicrograph of rat testis section stained with apoptotic P53 expression in different groups. A: Faint positive reaction for P53 expressions in the Leydig cells in the control (G1) group. B\&C: Testes sections in Amitriptyline treated rat group $(\mathrm{G} 2)$ showed a strong positive reaction for P53 expressions in the Leydig cells.

Also, Mariola et al. (2013) elucidated that amitriptyline may be responsible for the occurrence of a male's sexual dysfunction and reproductive toxicity that can alter essential sex hormones homeostasis. Besides, this study showed sperm abnormalities, disturbance and not a regular cycle of spermatogenesis in seminiferous tubules, a significant decrease in the number of spermatogenic cells in the seminiferous tubules, marked thickened in the basement membrane, moderate vacuolar degenerative changes in the cytoplasm of the spermatogenic epithelium and the Sertoli cells, decrease and abnormal distribution of spermatozoa was seen in the lumen of the seminiferous tubules and a significant decrease in the numbers of Leydig cells.

Also, amitriptyline induced P53 apoptotic protein activity in testicular tissue. That result was following Abd-El Maksoud et al., (2010) who concluded in his study that the use of a high dose of amitriptyline led to a reduction in the productive functions of the testis proved by decreased both hormonal levels and spermatic abnormalities with histopathological changes of testicular tissue. Also, Soghra et al., 2008 concluded that amitriptyline in high dose produced a significant decrease in testosterone and prolactin levels as well as a dramatic decrease in the spermatic count which was evident by morphologically changes in the testicular tissue including focal pyknosis, damaged spermatogonia lining cells and absent spermatids in seminiferous tubules.

\section{Conclusion}

Amitriptyline induces mischievous alters in testicular tissue that proved reproductive hormones maladjustment, sperm abnormalities, histopathological lesions and P53 protein expression.

\section{References}

Abd-Elmaksoud M, Afify M, Mosa T, Elshaer M, Kotb N. (2010): Differential effects of amitriptyline treatment on testicular and liver functions in adult male rats. New York: Science Journal; 3(3):10-18

Adamkovicova M, Toman R, Martiniakova M, Omelka R, Babosova R, Krajcovicova V, Grosskopf B, Massanyi P. (2016): Sperm motility and morphology changes in rats exposed to cadmium and diazinon. 
Reproductive Biology and Endocrinology. 14(1):42.

Badr El- Din S, Abd-El Aty AO. (2012):

Biochemical and immunocytochemical studies of the testicular changes after treatment with adauloxetine hydrochloride and the possible protective effects of omega 3 in adult rat model of depression, A. A. M. J., 10(3):264-300.

Bahmanpour S, Khooshnood MJ, Namavar MR, Bastia A. (2009): toxicological effects of amitriptyline on sex hormone level of male rats, Toxicology letters, 180(S):232-246.

Bancroft JD, Gamble M (2002): "Theory and Practice of Histological Technique". (5th edition), Churchill Livingstone, Edinburg, London.

Beverly K, Shailesh J, Madhukar H, Trivedi MD. (2005): Depression and Pain Implications for Symptomatic Presentation and Pharmacological Treatments Psychiatry (Edgmont), 2(5): $12-18$.

Clayton AH, Montejo AL. (2006): Major depressive disorder, antidepressants, and sexual dysfunction. J. Clin. Psychiatry., 67 (6):33-37.

DeLacerda L, Kowarski A, Johanson AJ. (1973): Integrated concentration and circadian variation of plasma testosterone in normal men, J. Clin. Endocrinol. Metab., 37:66-71.

Derogatis LR, Burnett AL. (2008): The epidemiology of sexual dysfunctions. J. Sex Med., 5(2):289-300.

Duhau L, Grassi J, Grouselle D. (1991): An enzyme immunoassay for rat prolactin: application to the determination of plasma levels, J. Immunoassay., 12(2), 233-250.

Hajhashemi V, Sajjadi SE, Zomorodkia M. (2011): Antinociceptive and antiinflammatory activities of Bunium persicum essential oil, hydroalcoholic and polyphenolic extracts in animal models. Pharm. Biol., 49,146-151.

Khurshid F, Govindasamy J, Khalilullah H, Nomani MS, Shahid M, Ain MR, Alsultan MS. (2017): Effect of herb-drug interactions of Bacopa monnieri Linn. (Brahmi) formulation on the pharmacokinetics of amitriptyline in rats. Braz. J. Pharm. Sci., 3(4):e17072.

Lewis RW, Fugl-Meyer KS, Corona G, Hayes RD, Laumann EO, Moreira ED, Rellini AH, Segraves T. (2010): Definitions/epidemiology/risk factors for sexual dysfunction. J. Sex Med., (4 Pt 2):1598-1607.

Mariola H, Monika GG, Anna G, Ewa J. (2013): Influence of combined therapy with rosuvastatin and amitriptyline on the oxidative-reduction status in rats. Acta Poloniae Pharmaceutical Drug Research, 70(5):913-917.

Mickle A, Kannamapalli P, Bruckert M, Miranda A, Banerjee B, Sengupta JN. (2012): Pronociceptive effect of 5-HT 1A receptor agonist on visceral pain involves spinal N-methyl-D-aspartate (NMDA) receptor. Neuroscience., 219:243-254.

Millan MJ. (2002): Descending control of pain. Prog. Neurobiol., 66(6):355-474.

Odell WD, Ross GT, Rayford PL. (1981): Radioimmunoassay for luteinizing hormone in human plasma or serum: physiological studies. J. Clin. Invest., 46,248-255.

Odell WD, Swerdloff RS, Bain J, Wollesen F, Grover PK. (1974): The effect of sexual maturation of testicular sensitivity to $\mathrm{LH}$ stimulation of testosterone secretion in the intact rat. Endocrinology, 95,1380.

Otaka M, Jin M, Odashima M, Matsuhashi T, Wada I, Horikawa Y, Komatsu K, Ohba R, Oyake J, Hatakeyama N, Watanabe S. (2005): New strategy of therapy for functional dyspepsia using famotidine, mosapride and amitriptyline. Aliment Pharmacol. Ther., 21 (2): 42-46.

Owens MJ, Bremner JD, Licinio J, Darnell A, Krystal JH, Southwick SM, Nemeroff CB, Charney DS. (1997): Elevated CSF corticotropin-releasing factor concentrations in posttraumatic stress disorder. Am. J. Psychiatry., 154(5):624629.

Rogan SC, Roth BL. (2011): Remote control of neuronal signalling. Pharmacol.

Rev., 63:291-315.

Soghra B, Mohammad J, Hamid K, Mohammad R, Amin B. (2008): Toxicological effects of amitriptyline on sex hormone level of male 
rats. Abstracts / Toxicology Letters 180S. S32-S246.

Tondo L, Baldessarini RJ. (2016): Depression following mania. Molecular Psychiatry, 21: 990.

Tousson E, Bayomy MF, Ahmed AA. (2018): Rosemary extract modulates fertility potential, DNA fragmentation, injury, KI67 and P53 alterations induced by etoposide in rat testes. Biomedicine \& Pharmacotherapy. 98: 769-774.

Wang YX, Sun Y, Feng W, Wang P, Yang P, Li J, Huang Z, Chen YJ, Liu C, Sun L, Yue J. (2016): Association of urinary metal levels with human semen quality: A crosssectional study in China. Environment international. 1(91):51-59.

Williams VSL, Edin HM, Hogue SL, Fehnel SE, Baldwin DS. (2010): Prevalence and impact of antidepressant-associated sexual dysfunction in three European countries: replication in across-sectional patient survey, Journal of Psychopharmacology, 24(4):489-496. 